Journal of World Englishes and Educational Practices (JWEEP)

ISSN: $2707-7586$

DOI: $10.32996 /$ jweep

Journal Homepage: www.al-kindipublisher.com/index.php/jweep

\title{
Flashcard Design for Helping Students in Learning Chinese Vocabulary
}

\author{
Le Ngoc Hieu ${ }^{1} \square$ Tran Khai Xuan $^{2}$, Ngo Hue Phuong ${ }^{3}$, Ung Phu Long ${ }^{4}$, Trieu Trach Nam $^{5}$ and Nguyen \\ Thien Ngan ${ }^{6}$ \\ 'Lecturer of IT, Faculty of IT, Ho Chi Minh City Open University, HCMC, Vietnam \\ ${ }^{2}$ Chair, Dept. of Teaching Methodology, Faculty of Chinese, Ho Chi Minh City University of Education, HCMC, Vietnam \\ ${ }^{3456}$ Students of Chinese Language, Faculty of Chinese, Ho Chi Minh City University of Education, HCMC, Vietnam
}

$\square$ Corresponding Author: Le Ngoc Hieu, E-mail: hieu.In@ou.edu.vn

\begin{tabular}{ll}
\hline ARTICLE INFORMATION & ABSTRACT \\
\hline
\end{tabular}

Received: 08 September 2021

Accepted: 14 October 2021

Published: 31 October 2021

DOI: 10.32996/jweep.2021.3.10.2

\section{KEYWORDS}

Chinese Vocabulary, Learn

Chinese, Anki App, Flashcard

Design
The strong rise of the globalization trend makes most students want to learn other languages than English. Many students have chosen Chinese as their second foreign language because China is one of the world's largest economies today. Learning vocabulary is one of the important factors that require much investment from the learners so that they need to find a suitable and effective learning method for themselves. To help Chinese learners learn vocabulary in an easier and more effective way, we would like to propose an approach of Designing online flashcards to help students learn Chinese vocabulary. This proposal is supported by Anki software. We design a set of Chinese vocabulary flashcards on this platform based on pre-compiled content. With the assisting of flashcards in learning Chinese, we can help the learners learn Chinese vocabulary more conveniently and more effectively. To evaluate this approach, we asked the learners for using a set of flashcards that we designed on the Anki app. The joining learners in this study are the $46^{\text {th }}$ generation students, freshers in Chinese learning, in the Chinese Faculty at HCMUE. The survey results show that the majority of users are satisfied with their experiences on online flashcards, and they see it much helpful for learning Chinese vocabulary.

\section{Introduction}

Going along with the current trends of globalization and technology integration, Chinese gradually becomes an important language which is the most people using it. That is the reason why there are too many people learning Chinese, and this number is going to be increased rapidly day by day. To help and support the learners in learning Chinese, learning vocabulary is a very extremely necessary for Chinese learners. Vocabulary is the beginning of the foreign language learning process. It is a great foundation and a good basement for listening, speaking, reading, and writing skills. Chinese vocabulary includes nouns, verbs, adjectives, pronouns, quantifiers, auxiliary verbs, adverbs, prepositions, conjunctions, auxiliary verbs, exclamation words, index words, words of quantity, etc.

To learn Chinese vocabulary, we have many ways, many aids, or many technologies for this purpose. Depending on the teachers or the curriculum program, the learners can choose their own suitable way to learn Chinese vocabulary with the best effectiveness. Flashcard is a very great tool that can help learners make vocabulary easier to remember and it helps the learner can easily imagine and visualize the words referring to. Flashcard is not only for kids or for beginners in learning Chinese but also a good way to help other learners, even professional Chinese language students. In this article, we use a tool named Anki App to design flashcards for junior students majoring in the Chinese language, to help them in learning new Chinese vocabulary. AnkiApp is a flashcard application which is developed by Admium corporation. The AnkiApp product is a cross-platform application, it can run on desktop or mobile platforms. This AnkiApp focused on educational applications, the languages supported mainly in English and Chinese. AnkiApp allows users to study vocabulary flashcards, create and design flashcards with text, audio, and images, or download pre-

Copyright: (C) 2021 the Author(s). This article is an open access article distributed under the terms and conditions of the Creative Commons Attribution (CC-BY) 4.0 license (https://creativecommons.org/licenses/by/4.0/). Published by Al-Kindi Centre for Research and Development, London, United Kingdom. 
made cards. We use AnkiApp to design Flashcards for Chinese learners, especially for $1^{\text {st }}$-year students majoring in the Chinese language at HCMUE, and we see how they learn and enjoy the flashcards.

To conduct this article, we would divide it into 5 sections. Section 1 is the introduction of this study. In section 2 we will present the literature review of this study: learning vocabulary and learning Chinese vocabulary, flashcards and Chinese flashcards, and Anki App. In Section 3, we would like to introduce our approach and the methodology of this study. The next section is section 4, we will present the evaluation result from students and discussion about it. Section 5 is the paper's conclusion.

\section{Literature Review}

\subsection{Learning vocabulary and learning Chinese Vocabulary}

To understand and explore a new language, learning vocabulary plays a very important role in the learners. We must understand the words with their ideas or concepts. The previous studies (Baumann \& Kame'enui, 2004; Pearson et al., 2007) showed that the correlation between vocabulary and reading comprehension is high, it is 0.6 to 0.8 . (Lubliner \& Scott, 2008) There are many levels of word understanding, from "I've never heard this word before," to "I know this word and can apply it in multiple contexts", as well as the knowledge about how to apply the best way to vocabulary learning (Beck et al., 2008).

As educators, we may concern about the development of a language. We can see that learning a language with oral language is easier than learning an academic language because it involves abstract literacy tasks and there are some concepts that cannot be described well in oral speech (Fang, Schleppegrell, \& Cox, 2006; Zwiers, 2007). The academic language is a second language (Solomon \& Rhodes, 1995), and all scholars want to learn it to access the academic content.

In learning a language, the learners may have various knowledge of words and vocabulary. Hart \& Risley's study (Hart \& Risley, 1995) showed that there are a lot of gaps between learners that they have or do not have enough words to understand the context. This study also reflects that these gaps directly affect the ability to learn a language, especially is the reading skill. The learner with stronger reading ability will get stronger in vocabulary and vice versa. To improve vocabulary learning, there are many teaching methodologies that address the gap and systematically teach vocabulary (Pearson et al., 2007; Zwier s, 2007). We can teach our students words, morphology, word origins, and some other important components that are related to the word. We can provide the various usages of the word in different situations and circumstances; it can be the teachers' teaching vocabulary strategy. Teachers can flexibly use some other techniques or teaching instruments to help improve learning vocabulary. We can generally imagine that one student can learn 300 to 400 words per year (Beck et al., 2008).

And studies show that teachers not only directly instruct the new word to the students but also can indirectly instruct these vocabularies via many other kinds of teaching activities such as reading, playing, discussing, etc. (Cunningham \& Stanovich, 2001; Nagy \& Herman, 1985). We can encourage the student's learning vocabulary with playing activities, participation in real word communication, and some other aids such as images, videos, music... (Beck et al., 2008; Graves \& Watts- Taffe, 2008).

With the development of technologies and communication, the teachers can apply the new ways of teaching methods, take advantage of digital tools, media, and internet-based things, to develop the vocabulary teaching strategy.

In a study of Learning Chinese Vocabulary (Fu, I.P., 2005), the author has focused on the strategies that native English speakers use as they learn to speak and write Chinese vocabulary words in the first year of an elementary Chinese class. From this study, we can understand that students used different ways to learn Chinese, some students get easier learning new words with sound, and some get better with visualized wording. However, most students used combinations of audio, visual, and kinesthetic learning techniques to learn new words. Besides that, students also enjoyed the art of Chinese characters and enjoyed writing them.

With learners whose mother tongue is an alphabet-based system, Learning Chinese vocabulary is a big challenge. There are many researchers who have been investigating Chinese vocabulary learning from both points of view: psycholinguistic and pedagogical. A study by Jing Yan (2020) has investigated some Chinese vocabulary learning strategies of English-speaking learners. With the participation of eight students in the UK, the author showed us that the students like to use orthographic strategies, semantic strategies, memory strategies, phonological strategies, and metacognitive strategies. This study suggests that Chinese vocabulary learning strategies need to be described in a holistic manner wherein physical and mental actions involved in cognitive strategies and metacognitive strategies are all taken into consideration to inform strategy instruction.

\subsection{Flashcard and Chinese flashcard 2.2.1 Flashcard}

As we all know, Flashcards or Flash Cards are typical cards that include the information of words, numbers, or some images. They are used for teaching or studying in the classroom or in anywhere we want. People will write text on the front of the card for questioning and on the back of the card is the answer. We often use flashcards as an aid tool to help our learners absorb vocabulary 
more effectively. Flashcards also can be used to learn other things such as historical dates, formulas, or whatever can be described in images or text. Flashcards nowadays are widely used. They are playing an important role as an aid of memorization by visualized repetition.

In teaching and learning a foreign language, Flashcard is used at the elementary level, and it is usually chosen to increase the students' vocabulary. It will make the student interested in studying vocabulary because most of them like to play such a card. According to a previous study, a flashcard (Cross, 1991) is a simple picture on a piece of card or paper, and it is probably the most widely used visual aids for teaching a language. We can understand that a flashcard is one type of media, and it can help the teacher to teach English easier. Flashcards can be potential in teaching vocabulary because the use is very simple and the effect is very good at visualization. So, the teacher can use flashcards and make the students more active during the teaching and learning process. Flashcards are some kinds of media that can be used by the teacher in the classroom.

\subsubsection{The effectiveness of flashcards}

Flashcards are a very effective review tool. According to a scientific research review of Brainscape (2021), flashcards can be very effective study materials. Firstly, they can engage in "active recall" due to the function front and back of the flashcard. Besides, flashcards also engage learners' metacognition. Researchers find that applying metacognitive strategies tends to make memories deeper into people's knowledge and leads to better learning outcomes. Finally, flashcards allow for confidence-based repetition.

\section{The science behind Brainscape.}



Figure 1. Flashcards are based on active recall, metacognition, and spaced repetition (https://www.brainscape.com/)

Not only is highly effective but flashcards are also a dynamic learning method. With a compact design, learners can carry flashcards with them and use them anytime, anywhere. In some countries with developed education such as Canada, Singapore, Korea, USA, ... they have many advanced methods that make it very easy to see students using flashcards in public areas. . They use them when waiting for the bus, taking a break, having lunch or watching before going to sleep... to absorb more as well as review knowledge in their spare time.

\subsection{Chinese flashcard}

In the process of learning and teaching Chinese, it is a good idea to start using Chinese flashcards. For many Chinese language learners, learning and knowing the best use of vocabulary are not easy at all. With flashcards, we can help Chinese learners improve much for their vocabulary. In fact, flashcards are such a successful learning device that Chinese flashcard has brought to the learners. Using flashcards for learning Chinese vocabulary is improving and it is a modern learning style, the style of flashcards that will work best for Chinese vocabulary learners. With the advantages of technologies, we now can have many options for using digital flashcards. These take all the previously established advantages associated with flashcards and add on built-in dictionaries, pronunciation guides recorded by native speakers, touchscreen interfaces, and more.

Whether you are studying for the HSK or for an upcoming vocabulary quiz, flashcards are a powerful tool that can help you meet your Chinese language learning goals. Paper cards and mobile apps both get great results, but they come with different strengths and weaknesses. 


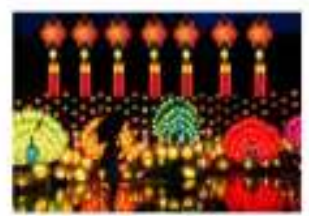

中国节日 (Chinese Festival)

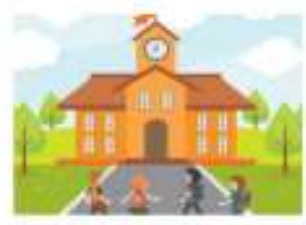

学特 (School)



水果 (Fruits)

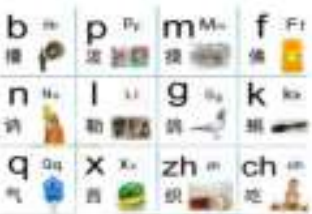

패슴 (Pinyin)

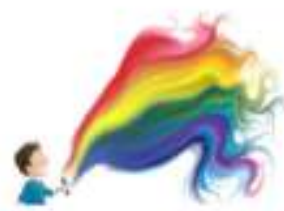

醁量 (Colors)



被菓 (Vegetables)

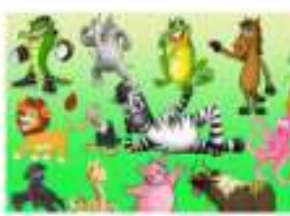

动物 (Animals)

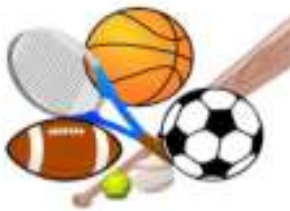

远动 (Sports)



家 (Family)



声物 (Plants)

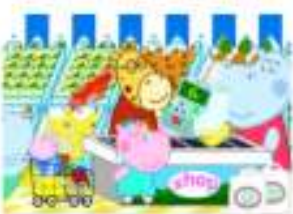

买东西 (shopping)

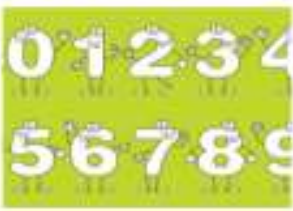

数字 (Number)

Figure 2. Chinese Flashcards (https://www.digmandarin.com/mandarin-chinese-flashcards)

\subsection{Anki application}

\subsubsection{Anki app}

AnkiApp (www.ankiapp.com) is a flashcard application developed by Admium corporation, based in the United States since 2014 AnkiApp product is a cross-platform, language-supported desktop and mobile educational application for mobile devices. Mainly in English and Chinese and designed according to the principle of a distributed system to seamlessly synchronize multiple active devices with a network connection. The term "Anki" is a Japanese word that means "remember". Anki is a free and open-source flashcard program that uses spaced repetition, a technique from cognitive science for quick and lasting memorization. AnkiApp allows users to study vocabulary flashcards in their spare time, create flashcards with text, audio and images, or download premade cards on AnkiApp's database. Learning will be extremely efficient thanks to AnkiApp's unique algorithm. In addition, AnkiApp can automatically backup and sync with all your devices through the cloud.

AnkiApp allows users to download more than 80 million vocabulary flashcards available on its database through the software's search engine. Most of the data from AnkiApp is censored from the server. Secondly, AnkiApp software helps users to test their knowledge quickly and effectively. Because, when using AnkiApp software, after each user completes learning, there will be a rating system with a corresponding rating scale for four options displayed on the interface about the user's understanding level. For learned vocabulary, specifically as follows:

Table 1. The levels of understanding vocabulary

\begin{tabular}{|l|l|}
\hline Selection & Meaningful \\
\hline Fail & The effect is not as expected, the vocabulary will appear again in about 10 minutes \\
\hline Hard & Works as expected by users, but not sure, vocabulary will reappear in 2 days \\
\hline Good & $\begin{array}{l}\text { As effective as users expect, but not sure if I can use the vocabulary fluently, the } \\
\text { vocabulary will reappear after 3 days }\end{array}$ \\
\hline Easy & $\begin{array}{l}\text { As effective as users expect and able to use vocabulary fluently, vocabulary will } \\
\text { reappear in 4 days }\end{array}$ \\
\hline
\end{tabular}

Thirdly, after each vocabulary study, AnkiApp will display an assessment table analyzing the user's vocabulary learning that day, including the following contents: the average number of daily vocabulary cards learned, the number of vocabulary cards per day learned, evaluate the learning efficiency per day (percentage). 


\subsubsection{Main features of AnkiApp}

AnkiApp makes learning effective. At the core of the Anki app is an advanced algorithm, developed by the old neuroscientist to save users time. When users use AnkiApp, the application will show the user's understanding of each flashcard, then prioritize the user, so users can focus on studying and learning. Flashcards that they don't know, not sure to save time but at the same time achieve high learning efficiency.

AnkiApp contains a rich source of available data. Users can start learning right away on AnkiApp with pre-made flashcards. AnkiApp includes a whole collection of built-in public flashcard sets. Users can download more data with more than 80 million memory cards available from Quizlet and other sources. In addition, if the user has previously used the AnkiWeb platform to store flashcards, AnkiApp can also import data from there.

AnkiApp allows users to create rich content. Anki app allows users to create their own memory cards on any device. Create cards easily by entering the desired content on the front and back of each card. In addition to traditional text, users can add images and sounds to their flashcards.

AnkiApp allows cloud access. The Anki app syncs seamlessly with the cloud, so users can create flashcards on one device and then sync them for use on another. In addition, users can use their personal AnkiApp account to access the AnkiApp website for free. It works on any computer or mobile device running the latest Chrome, Safari, or Opera browsers.

AnkiApp supports multiple languages. AnkiApp is ready to support application installation for more than 155 countries or regions around the world. AnkiApp is available in English, French, German, Traditional and Simplified Chinese, Portuguese, and Romanian on all supported platforms.

\section{Methodology}

\subsection{Flashcard Design}

\subsubsection{Select, edit and prepare vocabulary}

In order to serve the purpose of supporting elementary Chinese learners, we have selected all vocabulary at HSK-1 level and HSK2 level from the textbooks: Standard HSK 1 and HSK 2 (HSK 标准教程 1 and HSK 标准教程2). The results of synthesis and composing these words show that, in total, there are about 345 Chinese words. They are noun, verb, adjective, pronoun, quantifier, auxiliary verb, adverb, preposition, conjunction, auxiliary word, exclamation word, numeral word, and quantity words.

\subsubsection{Translate Chinese words into Vietnamese}

In order to translate and bring the meaning of the words with the most accurate and most appropriate, we compile and edit the meaning of the words from the textbooks "HSK 1,2 and 3 Vocabulary Handbook - Explanation and usage", and then we combined with the teachers' translation of the words from HSK 1 and HSK 2 standard textbooks.

\subsubsection{Add phonetic transcription and word categories for the Chinese words}

Chinese is not a Latin-based character language. It must have a transcription of phonetics to help learners know how to pronounce. So, we add the phonetic transcription (pinyin system) and word classification based on the standard textbooks: HSK 1 and HSK 2. At the same time, in order to create a visual impression and make it convenient for learners to distinguish between word categories, we use different colors for each word category (part of speech).

Table 2. Word category and color

\begin{tabular}{|l|l|}
\hline Word category (part of speech) & Color for distinguishing \\
\hline Noun & \\
\hline Verb & \\
\hline Pronoun & \\
\hline Preposition & \\
\hline Conjunctions & \\
\hline Quantifier & \\
\hline Adverb & \\
\hline Adjective & \\
\hline
\end{tabular}




\begin{tabular}{|l|l|}
\hline Interjection & \\
\hline Classifier & \\
\hline Numeral & \\
\hline Multi-grammar-functional word & \\
\hline Auxiliary word & \\
\hline
\end{tabular}

\subsubsection{Give phrase and example sentence for the Chinese words}

We select and compose the phrases and give example sentences for the words in the flashcards which are from the standard textbooks: HSK 1 and HSK 2, "1, 2 and 3 Vocabulary Handbook - Explanation and Usage" textbook and online Pleco dictionary. The phrases are short and easy to remember, and the example sentences are presented in the form of simple sentences or popular conversations. This meets the criteria of simplicity and ease of understanding, which learners can apply in daily communication.

Word matching of a flashcard is one of the most highlights of our objectives, which aims to help learners have a better understanding of the usage of Chinese words. The combination between word and flashcard will be according to the criteria of structural relationship of the phrase containing the selected word. We use the criteria system of phrases structural relation is based on the Chinese grammar textbook (现代汉语概论) composed and edited by the author 陈阿宝. Words are grouped into clusters based on the grammatical functions of the word class of the word, and each word is composed of at least two phrases and at most three, as follows:

Table 3. Phrase of combination, an example of word and Flashcard design

\begin{tabular}{|c|c|c|}
\hline Part of speech & Rules of phrase combination & Example \\
\hline \multirow{3}{*}{$\begin{array}{l}\text { Noun } \\
\text { 名词 }\end{array}$} & $\begin{array}{l}\text { Endocentric Phrase } \\
\text { 偏正词组 }\end{array}$ & $\begin{array}{l}\text { 一本书 A book } \\
\text { 好看的电影Good movies }\end{array}$ \\
\hline & $\begin{array}{l}\text { Prepositional phrase } \\
\text { 介词词组 }\end{array}$ & 在学校at school \\
\hline & $\begin{array}{l}\text { Verb-object phrases } \\
\text { 动宾词组 }\end{array}$ & 看电影watch movie (Cinema) \\
\hline \multirow{3}{*}{$\begin{array}{l}\text { Verb / 动词, } \\
\text { Modal Verb / 能源动词, } \\
\text { Auxiliary Verb } \\
\text { 助动词 }\end{array}$} & $\begin{array}{l}\text { Verb-object phrases } \\
\text { 动宾词组 }\end{array}$ & 买书Buy book \\
\hline & $\begin{array}{l}\text { Verb-complement phrase } \\
\text { 动补词组 }\end{array}$ & 吃完slam \\
\hline & $\begin{array}{l}\text { Endocentric Phrase } \\
\text { 偏正词组 }\end{array}$ & $\begin{array}{l}\text { 认真（地）工作 } \\
\text { Seriously working }\end{array}$ \\
\hline \multirow{3}{*}{$\begin{array}{l}\text { Pronoun } \\
\text { 代词 }\end{array}$} & $\begin{array}{l}\text { Endocentric Phrase } \\
\text { 偏正词组 }\end{array}$ & $\begin{array}{l}\text { 我们的学校 } \\
\text { Our school }\end{array}$ \\
\hline & $\begin{array}{l}\text { Locational prepositional phrase } \\
\text { 方位词组 }\end{array}$ & 家里at home \\
\hline & $\begin{array}{l}\text { Prepositional phrase } \\
\text { 介词词组 }\end{array}$ & 在这儿here \\
\hline $\begin{array}{l}\text { Preposition } \\
\text { 介词 }\end{array}$ & $\begin{array}{l}\text { Prepositional phrase } \\
\text { 介词词组 }\end{array}$ & 在教室In the class \\
\hline $\begin{array}{l}\text { Conjunctions } \\
\text { 连词 }\end{array}$ & $\begin{array}{l}\text { Coordinative phrase } \\
\text { 联合词组 }\end{array}$ & 我和你Me and you \\
\hline $\begin{array}{l}\text { Quantifier } \\
\text { 量词 }\end{array}$ & $\begin{array}{l}\text { Endocentric Phrase } \\
\text { 偏正词组 }\end{array}$ & 一道菜A dish \\
\hline $\begin{array}{l}\text { Adverb } \\
\text { 副词 }\end{array}$ & $\begin{array}{l}\text { Endocentric Phrase } \\
\text { 偏正词组 }\end{array}$ & $\begin{array}{l}\text { 不是Not } \\
\text { 很喜欢Like so much }\end{array}$ \\
\hline Adjective & Endocentric Phrase & 好学生good student \\
\hline
\end{tabular}




\begin{tabular}{|l|l|l|}
\hline \multirow{2}{*}{ 形容词 } & 偏正词组 & \\
\cline { 2 - 3 } & $\begin{array}{l}\text { Verb-complement phrase } \\
\text { 动补词组 }\end{array}$ & 跑得快Run very fast \\
\hline $\begin{array}{l}\text { Interjections } \\
\text { 叹词 }\end{array}$ & $\begin{array}{l}\text { Do not make a phrase, give } \\
\text { example in a short conversation. }\end{array}$ & \\
\hline $\begin{array}{l}\text { Numeral } \\
\text { 数词 }\end{array}$ & $\begin{array}{l}\text { Endocentric Phrase } \\
\text { 偏正词组 }\end{array}$ & $\begin{array}{l}\text { 一个小时One hour } \\
\text { 两个人Two people }\end{array}$ \\
\hline $\begin{array}{l}\text { Auxiliary word } \\
\text { 助词 }\end{array}$ & $\begin{array}{l}\text { Verb-complement phrase } \\
\text { 动补词组 }\end{array}$ & $\begin{array}{l}\text { 看了一个小时 } \\
\text { Watched for an hour }\end{array}$ \\
\hline
\end{tabular}

Image using for the word: we selected the images for illustration for the words from the free resources (free Pexels and Freepik image repositories), and retouched, sketched them to the right size using Photoshop software. With some special cases, to illustrate vocabulary more intuitively and vividly, we add animation or short video clips to express the meaning of the words. Animations are selected from Giphy's free animation stock or designed by our team using Gif Maker.

Pronunciation sound of the word: The most special feature of this online flashcard is the integration of audio files. It helps learners listen to the exact pronunciation of the word without using an electronic dictionary while learning new words via our flashcards. This is convenient and saves time for learners. The audio files for pronunciation sound are selected from the audio discs of the standard textbooks HSK 1 and HSK 2.

The writing part of the word, Chinese characters: Based on the number of compiled vocabularies, we selected the images which show how to write the Chinese characters respectively from the website Strokeorder.info. We add these images for the writing part of all the vocabulary words in the flashcards.

\subsubsection{Design and implement word into the flashcard}

We implement the flashcard sets onto the AnkiApp platform using the interface tool supported by Anki. According to our design, each card in a flashcard set is divided into two parts: the front side and the backside. The contents of a vocabulary card are shown on these two sides respectively. Besides, the content is designed by our team based on the specific requirements and previous research of the team.

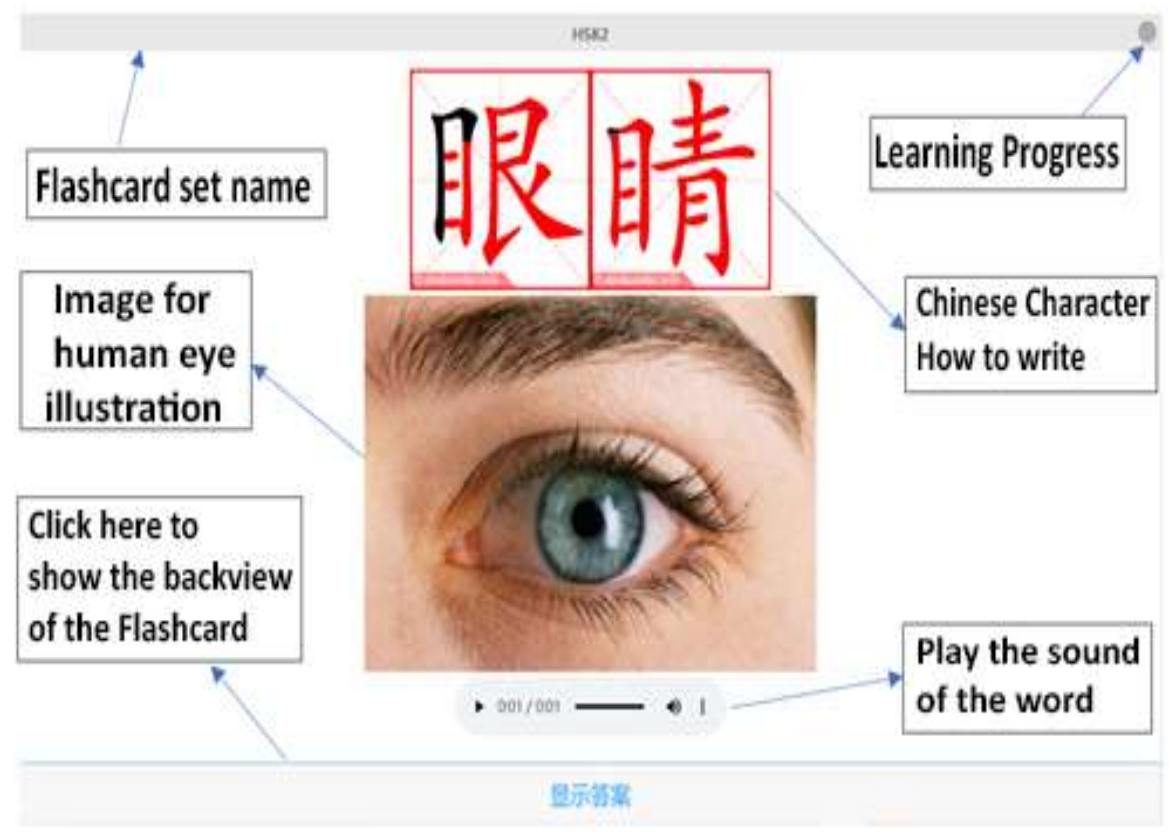

Figure 3. Front view of the flashcard "eye - 眼睛" (computer screenshot) 




Figure 4. Back view of the flashcard "eye - 眼睛" (computer screenshot)

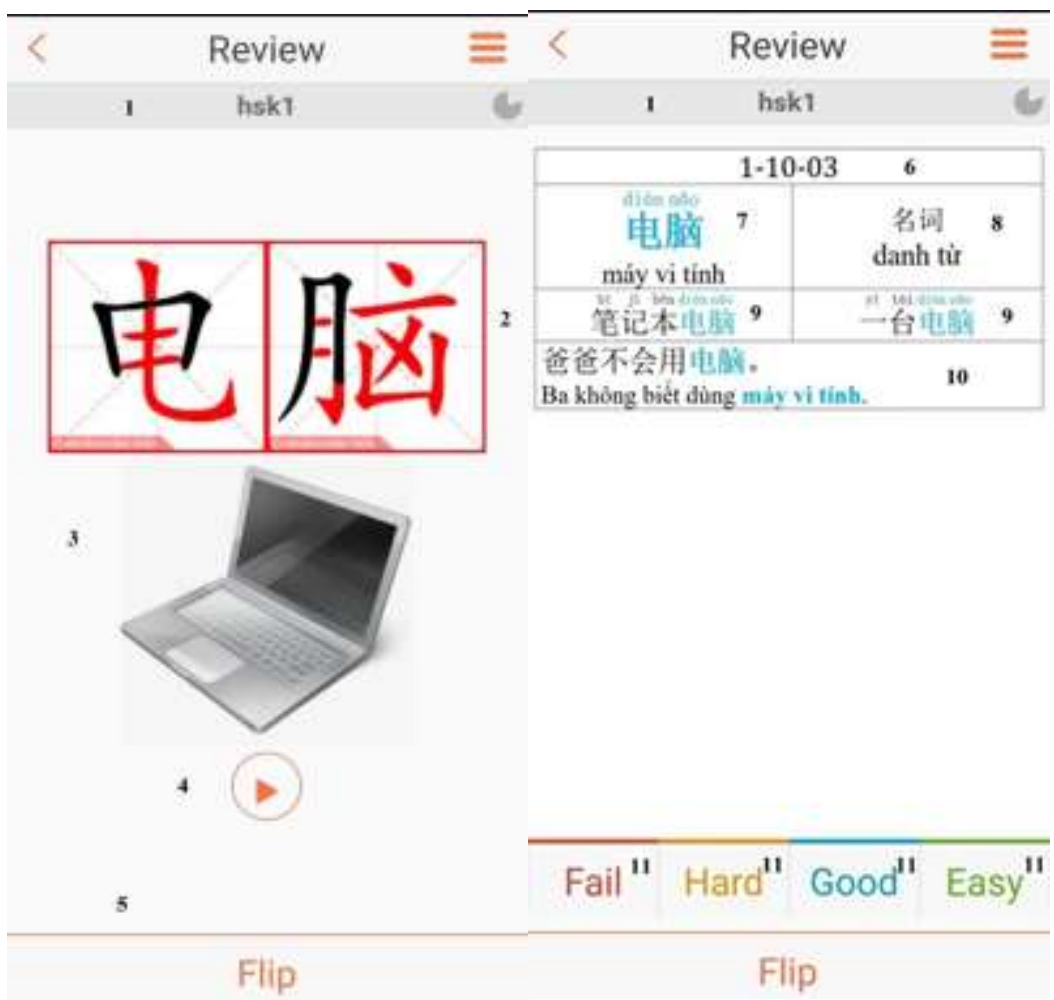

Figure 5. Front view and back view of the flashcard "computer - 电脑" (phone screenshot)

In figure 5, 1 is the name of the flashcard set; 2 is the form and how to write in Chinese character of the word; 3 is an illustration image closest to the word meaning; 4 is the sound file of the word; 5 is to click to display the back view of the flashcard. 6 is the ID of the word (this ID is generated based on the structure of HSK LEVEL- PART NUMBER-ORDER NUMBER OF WORD IN THE LESSON); 7 is the word and its meaning; 8 is the word category of the word (part of speech); 9 is a combination of words in phrases; 10 is the example of words; 11 are the scale to measure the effectiveness of word learning. 


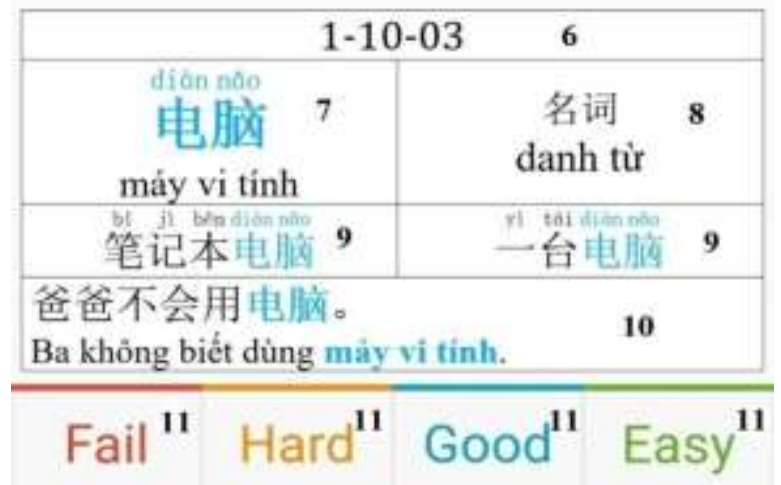

Figure 6. Back view of the flashcard "computer - 电脑" (design for mobile phones)

In addition, to support the user with the best, we provide responsive GUI for all kinds of devices, including phones and computers. With this approach, we adjust the size of the flashcard based on the device that users are using.

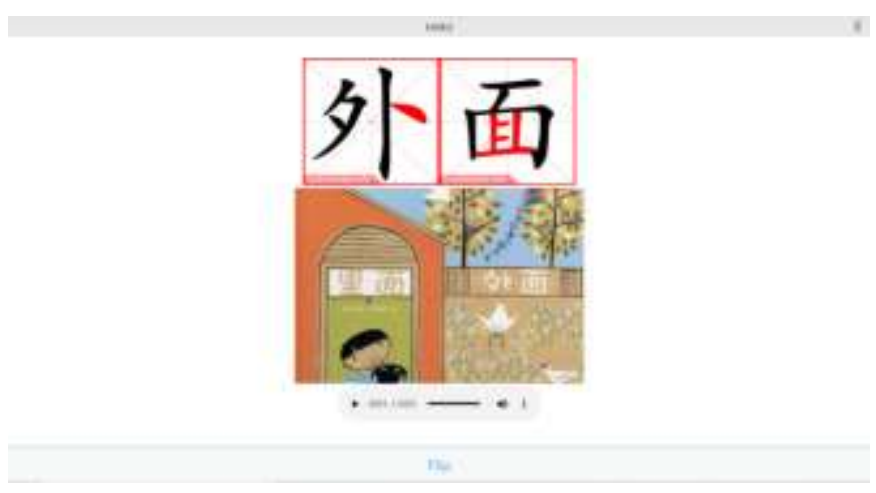

Figure 7. Front and back view of a flashcard.

\subsection{Product evaluation}

\subsubsection{Build a questionnaire survey for getting an evaluation}

The questionnaire that the research team used to survey is based on the method of Ho Dung and Trieu Phung Mai (2015). With this article, we take advantage of the theoretical basis to compile a practical survey questionnaire. Then we conduct the investigation of learners. Survey participants mainly are $1^{\text {st }}$-year students in Chinese Major. They will answer the questions based on 5 levels 1 to 5 according to the increasing level following the Likert scale. These 5 levels will reflect the attitudes of the participants for the statements made. Level 5 stands for "Strongly agree", level 4 stands for "Agree", level 3 represents "Neutral", level 2 represents "Disagree" and level 1 represents means "Strongly disagree".

Table 4. Evaluation questions for the survey

\begin{tabular}{|c|c|c|c|c|c|}
\hline \multirow[t]{2}{*}{ Question } & \multicolumn{3}{|c|}{$\begin{array}{l}\text { Evaluation } \\
\text { scale }\end{array}$} & \multicolumn{2}{|c|}{ Scoring } \\
\hline & 1 & 2 & 3 & 4 & 5 \\
\hline \multicolumn{6}{|l|}{ 1/ You are satisfied with the online flashcard with the existing design. } \\
\hline \multicolumn{6}{|l|}{$\begin{array}{l}\text { 2/ The content of the online flashcard set (Image, sound, word meaning, writing Chinese characters, } \\
\text { an example of sentence) is intuitive, vivid, and accurate. }\end{array}$} \\
\hline \multicolumn{6}{|l|}{ 3/ The layout of the flashcards is reasonable and scientific. } \\
\hline \multicolumn{6}{|l|}{ 4/ Online flashcards improve learning Chinese vocabulary. } \\
\hline \multicolumn{6}{|l|}{ 5/ The interface of the online flashcard platform is easy to use, simple to operate, and optimized. } \\
\hline \multicolumn{6}{|l|}{ 6/ Convenient online flashcard kit (can be used anywhere, integrated multimedia). } \\
\hline 7/ AnkiApp's learning efficiency evaluation system is reasonable and accurate. & & & & & \\
\hline
\end{tabular}

We also compiled 2 more short-answer questions to serve the purpose of direct surveys, collecting opinions of the users:

8/ What is the point of the online flashcard set that impresses you?

9/ What is the point of the online flashcard set that makes you feel unsatisfied? 


\section{Results and Discussion}

4.2.1 Survey

\subsubsection{Survey information}

For surveying, we select the first-year students K46 of the Chinese Department of the Ho Chi Minh University of Education to join the survey. We take the survey works around a half of a month, from March 13, 2021, to March 30, 2021. We use Google Form for the online survey and face-to-face interview for a random check. We have taken 100 records from K46 first-year students of the Chinese Department. We asked them to use the flashcards and do the survey. Then we conducted face-to-face interviews, 20 students were randomly selected from the initial 100 online.

\subsubsection{Survey results}

From the methods suggested above, we gave everyone a try, and then we did an online survey of 100 people and a face-to-face survey of 20 people. A survey by online questionnaire is one of the two methods that our team has chosen. To get the results, the form is not only convenient for survey participants, but also greatly supports the research team in making statistics, analyzing, and ensuring the accuracy of the collected data. Through the data collected from the survey, we will verify whether the group's flashcards are really effective in helping students learn Chinese vocabulary.



Figure 8. Distribution of agreement about Question No.1

In the first question, looking at figure 8 , we can see that the majority of answers agree with this idea (45.5\% and $41.6 \%$ are two proportions of the number, respectively. Survey participants chose to answer two levels of "Strongly agree" and "Agree"). However, in 100 survey participants, there are still cases of dissatisfaction in some aspects of the product, even if it is only $1 \%$, this proves that our product still has something that needs to be improved.

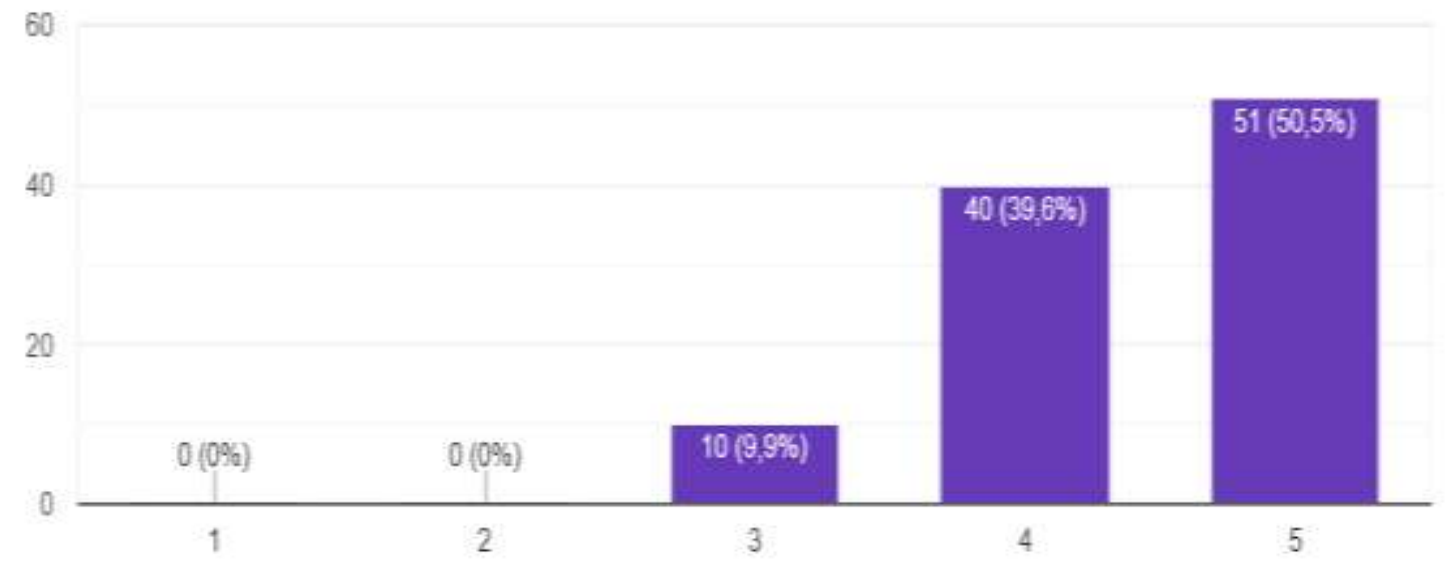

Figure 9. Distribution of agreement about Question No.2 
For the second question, similar to the first question, up to $90 \%$ of people agree that "The content of the online flashcard set is intuitive, vivid, accurate" in which the number of people who chooses "Strongly agree" accounted for more than half of the total survey participants (50.5\%). Thereby, it is possible to ensure the accuracy of the content of the flashcard set (including images, sounds, word meanings, pen, examples) which is one of the factors carefully invested by our team.

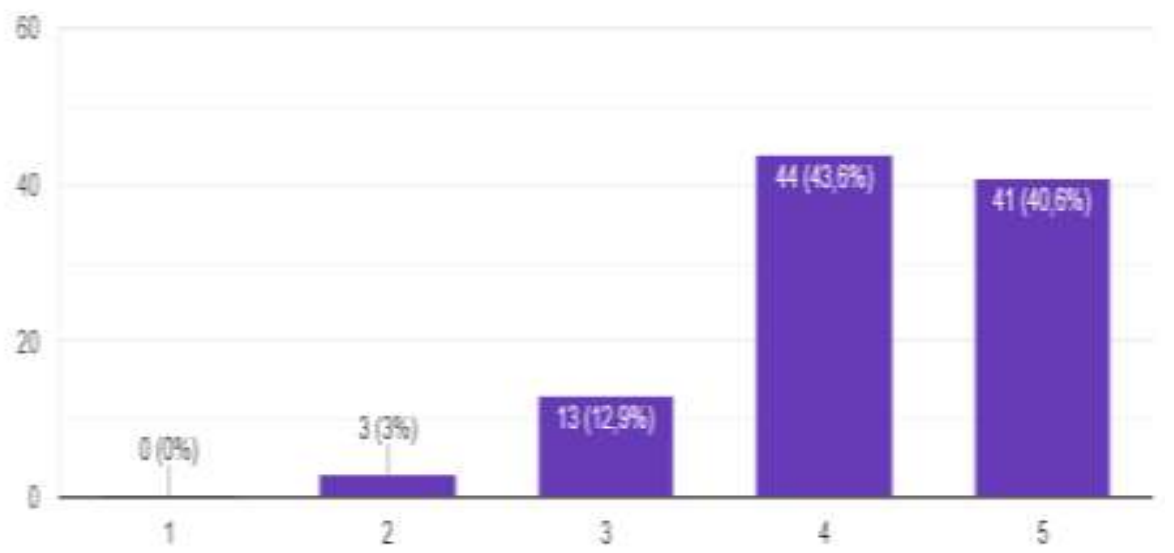

Figure 10. Distribution of agreement about Question No.3

In the third question, when surveying users about the layout and parts of the product, although the majority of survey respondents agree with this opinion ( $40.6 \%$ strongly agree and $43.6 \%$ strongly agree), there were three cases (3\%) disagreeing with this idea. If linked to the first question, then perhaps "Flashcard layout" is one of the factors that led to the emergence of a case of dissatisfaction with the flashcard set.

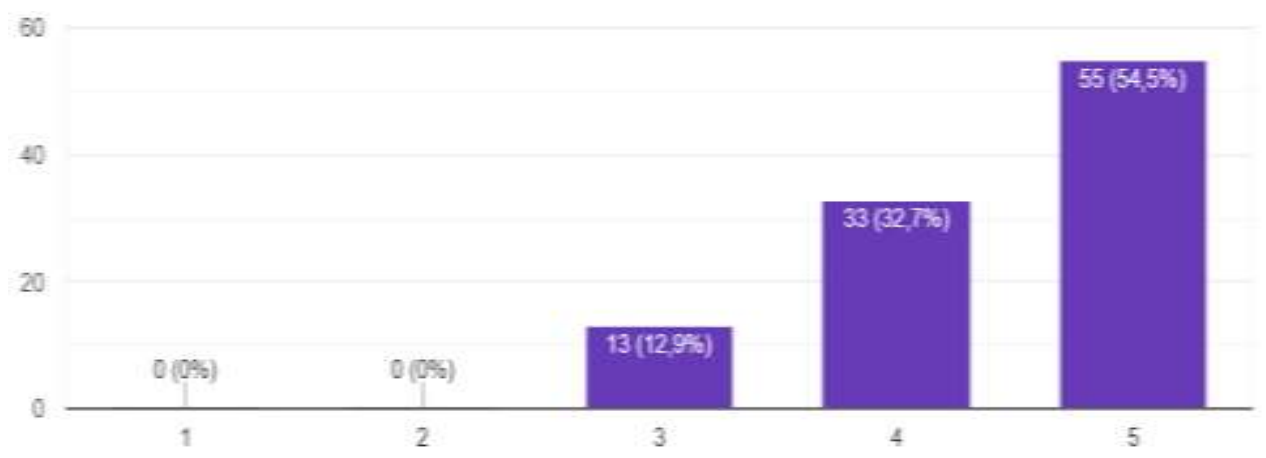

Figure 11. Distribution of agreement about Question No.4

When surveying the attitude of flashcard users towards the opinion "Online flashcards improve learning Chinese vocabulary.", up to 88 people agree with this idea, accounting for $89 \%$ of the total survey participants, no survey respondents chose "Disagree" or "Strongly disagree". And this shows that online flashcards are effective in "improving Chinese vocabulary learning."

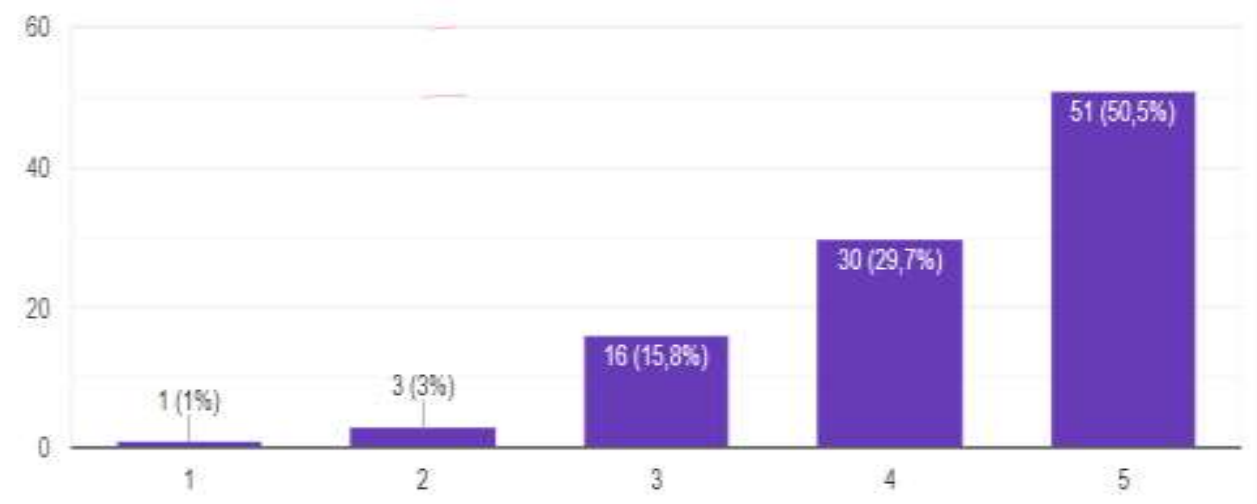

Figure 12. Distribution of agreement about Question No.5 
The content of the fifth question is related to the IT element of the product. Although on this question, the number of people agreeing with the opinion "The interface of the online flashcard platform is easy to use, simple to operate, and optimal." reached $80 \%$, but the appearance of $1 \%$ of users choosing "Strongly disagree". This number partly reflects the IT factor of the product, which is one of the shortcomings that need to be invested and improved.

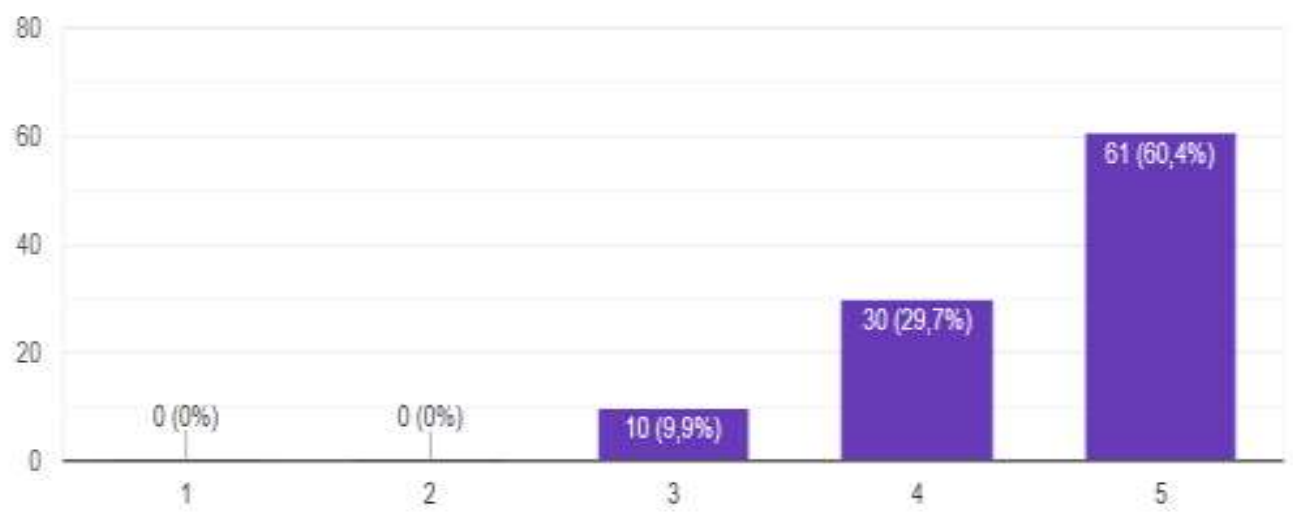

Figure 13. Distribution of agreement about Question No.6

With the sixth question, the majority of survey participants agree with this opinion (90.1\%). In which $60.4 \%$ of survey participants chose "Strongly agree", twice as many people chose "Agree", 6 times more than the number of people who chose "Normal" (9.9\%). This data proves that the flashcard set is very convenient, in line with most of the standards commonly found in IT products.

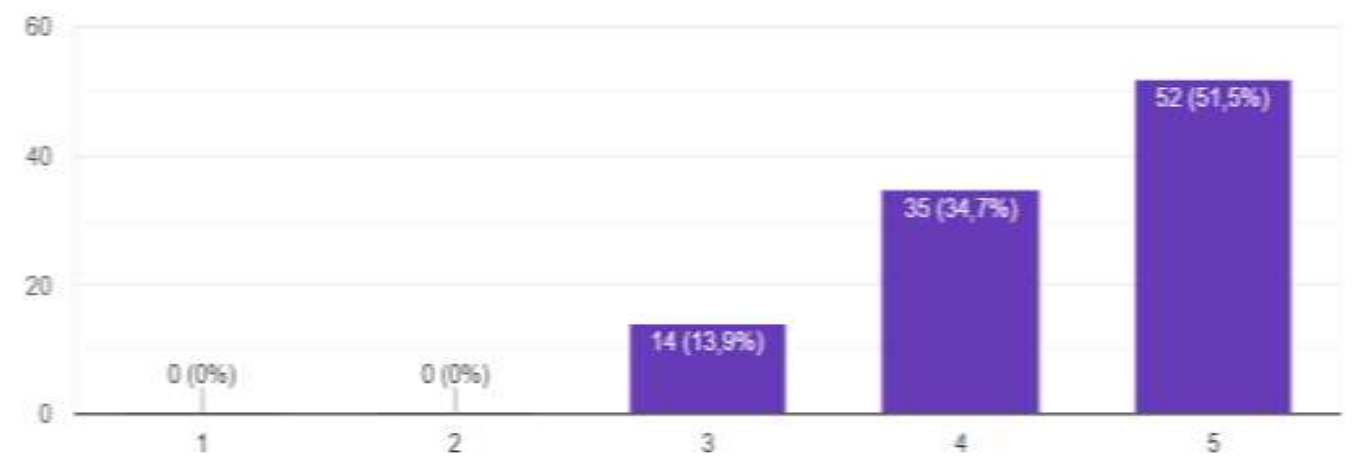

Figure 14. Distribution of agreement about Question No.7

AnkiApp's learning performance evaluation system is an advantage because the software is pre-designed at no cost to the user. Survey results show that up to $86 \%$ agree with this idea, of which "Strongly agree" accounts for more than half of the survey participants (51.5\%).

With the survey by face-to-face interview, we use to increase the reliability and authenticity of the data, it is also the basis for the research team to absorb the opinions of flashcard users. People participating in the survey by interview form were 20 random students, selected from 100 initially surveyed online. The questions used for face-to-face interviews are questions compiled in the form of short-answer questions so that respondents can prioritize the characteristics that impress them the most. And after conducting the interviews, our team synthesized the answers of the above subjects, the results were that the majority of participants who experienced the product found that the online flashcard set was effective in supporting learning Chinese vocabulary, and the most impressive features, in turn, are the contents of the flashcard set (images, sounds, pen,...); convenient, multimedia platform (integrates both audio and video on the same platform). Besides, when asked about the point of the flashcard set that makes users feel dissatisfied, there are some cases of commenting that the AnkiApp platform is a rather difficult platform to use, and this will affect the software. On their effectiveness in learning Chinese vocabulary when using the product. These comments also partly correspond to the percentage of people who "Strongly disagree" and "Disagree" about the technical aspects of the product.

In general, after conducting and analyzing the results of two kinds of surveys (online questionnaires and face-to-face interviews), we found that the flashcard set achieved the research goal - designing a set of online flashcards that are effective in helping students learn Chinese vocabulary. Regarding the content (images, sounds, word meanings, examples, etc.), the layout of the flashcard set satisfied the majority of users. On the technical issue, the convenience, the learning effectiveness evaluation system 
of the software are the points that make the product improve. However, the technology of the product still has limitations, which is the interface of the AnkiApp software. From there, it can be seen that whether it is a survey in the form of an online questionnaire or a face-to-face interview, the interface of the product is also an inadequacy that the team needs to pay attention to.

\section{Conclusion}

The research process to find a theoretical framework for designing a set of flashcards for learning Chinese vocabulary has shown the importance of learning vocabulary when learning a foreign language. It also tells us about the factors affecting learning vocabulary and the requirements to achieve in learning vocabulary. From there, the learner can choose the effective vocabulary learning method which is most suitable. Among these, learning vocabulary through online flashcards is a method that we find many advantages and is highly effective in supporting vocabulary learning. The idea to design an online flashcard set on AnkiApp requires users to have software experience and they can understand the operating principles of the software, then they can proceed to implement a set of Chinese vocabulary flashcards onto this platform. The finished product was put into the experiment and evaluated. Survey results show that most users are satisfied with their experiences on online flashcards. However, the product still has some limitations such as the initial use of the software requires users to spend time to understand the software principles, leading to some users finding the software difficult to use, and some users are not really satisfied with the flashcard set due to some reasons. This is unavoidable because AnkiApp is a free support software for users, the main idea is to design the content of each vocabulary learning card, so users need to take the time to learn about the usage of AnkiApp. However, this will be a valuable experience for us to do research further in the future. We need to integrate and develop our own tech for the product so that users feel easy to use and adapt to most of the learning process. In addition, because of the content copyright issue, the design team cannot directly display the link for users to receive the flashcard set, but when the user needs to use our flashcard set, they need to provide the email address for use. After receiving the e-mail, we send the user the accessing link and follow the instructions attached in the e-mail to receive the flashcard and start using it.

With this AnkiApp Flashcards approach, we still have a lot of limitations due to the free version of AnkiApp, we cannot develop and design the flashcards with more and more functions. Besides, users must depend on AnkiApp and its own structure to run the Flashcards, so it may take longer than we just only run the proposed Flashcards. Users also cannot access these flashcards if their internet is interrupted or disabled. For future works and development, we would add more vocabularies for this Flashcards app, the words are from the standard textbooks: HSK 3, HSK4, HSK 5, and HSK6. With more words, Flashcards can add more functions with a word such as idiom, synonyms, antonym, or other grammatical functions. The adding functions depend on the level of the word and the target audiences. We also plan to upgrade and build it as a learning product with features, especially using Al features to personalized users to help them identify their own weaknesses in learning vocabularies and word pronunciation. With this further target, we want to make the most usage of the advanced technologies for Chinese learners, especially starters with a new language, getting them more excited in this difficult language, Chinese.

Funding: This research received no external funding.

Acknowledgments: We are so grateful that the Ho Chi Minh City University of Education has enabled us to carry out this study. Besides, we would also like to express our sincere thanks to the people who have joined the surveyed and supported us to contribute to the results of this research.

Conflicts of Interest: The authors declare no conflict of interest.

\section{References}

[1] Baumann, J.F., \& Kame'enui, E.J. (Eds.). (2004). Vocabulary instruction: Research to practice. New York: Guilford

[2] Beck, I.L., McKeown, M.G., \& Kucan, L. (2008). Creating robust vocabulary: Frequently asked questions \& extended examples. New York: Guilford.

[3] Berne, J.I., \& Blachowicz, C.L.Z. (2008). What reading teachers say about vocabulary instruction. The Reading Teacher, 62(4), 314-323. doi:10.1598/RT.62.4.4

[4] Chall, J.S., \& Jacobs, V.A. (2003). The classic study on poor children's fourth-grade slump. American Educator, 27(1), 14-15, 44.

[5] Fang, Z., Schleppegrell, M.J., \& Cox, B.E. (2006). Understanding the language demands of schooling: Nouns in academic registers. Journal of Literacy Research, 38(3), 247-273. doi:10.1207/s15548430jlr3803_1

[6] Hart, B., \& Risley, T.R. (1995). Meaningful differences in the everyday experience of young American children. Baltimore: Paul H. Brookes

[7] Lubliner, S., \& Grisham, D.L. (2002). Cognate strategy instruction: Providing powerful literacy tools to Spanish-speaking students. In J. Fingon \& S. Ulanoff (Eds.), Learning from culturally and linguistically diverse classrooms: Promoting success for all students. New York: Teachers College Press.

[8] Lubliner, S., \& Scott, J.A. (2008). Nourishing vocabulary: Balancing words and learning. Thousand Oaks, CA: Corwin.

[9] Pearson, P.D., Hiebert, E.H., \& Kamil, M.L. (2007). Vocabulary assessment: What we know and what we need to learn. Reading Research Quarterly, 42(2), 282-296. doi:10.1598/RRQ.42.2.4

[10] Graves, M.F., \& Watts-Taffe, S. (2008). For the love of words: Fostering word consciousness in young readers. The Reading Teacher, 62(3), 185-193. doi:10.1598/RT.62.3.1 
[11] Fu, I-Ping P. (2005). Student Approaches to Learning Chinese Vocabulary. Virginia Polytechnic Institute and State University

[12] Yan, J. (2020). Chinese vocabulary learning strategies by English-speaking learners: A think-aloud study. Global Chinese, 6(2), $237-262$. https://doi.org/10.1515/glochi-2020-0013

[13] Cross, D. (1991). A Practical Handbook of Language Teaching.

[14] Khương Lệ Bình (chủ biên), Vương Phương, Vương Phong, Lưu Lệ Bình (biên soạn), bản dịch tiếng Việt: Nguyễn Thị Minh Hồng (2016). Giáo trình chuẩn HSK 1. NXB Tổng hợp thành phố Hồ Chí Minh.

[15] Khương Lệ Bình (chủ biên), Vương Phương, Vương Phong, Lưu Lệ Bình (biên soạn), bản dịch tiếng Việt: Nguyễn Thị Minh Hồng (2016). Giáo trình chuẩn HSK 2. NXB Tổng hợp thành phố Hồ Chí Minh.

[16] 陈啊宝（主编），吴中伟（副主编）(2002). 现代汉语概论，北京语言文化大学出版社.

[17] Hồ Dũng, Triệu Phụng Mai (2015). Mô hình phân tích và đo lường hiệu quả của dạy học trực tuyến. Tạp chí Nghiên cứu Giáo dục điện tử hoá. Số 10.

[18] Anki (software) Accessed (2021). Retrieved August 30, 2021, from https://vi.wikiqube.net/wiki/Anki_(software)

[19] Anki - powerful, intelligent flashcards. (2021). Anki Website. Retrieved August 20, 2021, from https://apps.ankiweb.net//

[20] Wikipedia contributors. (2021). Flashcard. Wiki. Retrieved August 20, 2021, from https://vi.wikipedia.org/wiki/Flashcard 